\title{
A case report of lymphangioma circumscriptum of the vulva
}

\author{
S Murugan, G Srinivasan, M C A Kaleelullah, Lewellyn Rajkumar
}

\begin{abstract}
Lymphangioma circumscriptum of the vulva mimicking condyloma acuminata is reported for its rarity.

\section{Introduction}

Lymphangioma circumscriptum is a localised group of thin walled and translucent vesicles resembling frog spawn. ${ }^{1}$ Axilla, adjacent chestwall, oral cavity and tongue ${ }^{2}$ are common sites. It is a form of nevus and recurrence even after surgery is common. The vulva is a rare site for lymphangioma circumscriptum and only four such cases have been reported in the literature.
\end{abstract}

\section{Case report}

An unmarried, 20 year old, female was referred to the department of sexually transmitted diseases (STD) of this hopsital in December 1990 as she had a progressive swelling of the genitals for 2 years. She had no sexual contact so far. She had undergone some irregular allopathic and native treatment for the present ailment. On examination, both labia majora and minora were swollen, hypertrophied, and hyperpigmented over which numerous greyish white vesicles were present. Swelling extended up to the right groin and perineal region. Clear fluid exudated from a punctured vesicle. Profuse white purulent discharge per vagina was present. The cervix was healthy. Investigation by wet film for Trichomonas vaginalis and Gram stain for gonococci were negative, but candidal filaments were seen in $\mathrm{KOH}$ preparation. Microfilaria were absent in a night peripheral smear. The Mantoux test was negative. Total and differential WBC count were within normal limits. Erythrocyte sedimentation rate was $15 \mathrm{~mm} / \mathrm{h}$ (Westegren). There was no evidence of pulmonary tuberculosis on a chest radiograph. VDRL slide test was non reactive.

A biopsy specimen from the lesion was stained with $\mathrm{H}$ and $\mathrm{E}$ and Elastica von Gisson and revealed hyperplasia of the epidermis with pigmentation. The dermis showed numerous dilated lymphatic and angiomatous spaces with proliferation of capillaries and an extensive lymphocytic and plasma cell infiltration. The diagnosis of lymphangioma circumscriptum was confirmed.

She was referred for plastic surgery. Vulvectomy was performed. She returned with a recurrence after 9 months. Once again the lesion was excised.

\section{Discussion}

Lymphangioma circumscriptum is a rare form of nevus, usually occurring at an early age but it may become clinically apparent up to 35 years and even later. ${ }^{7}$

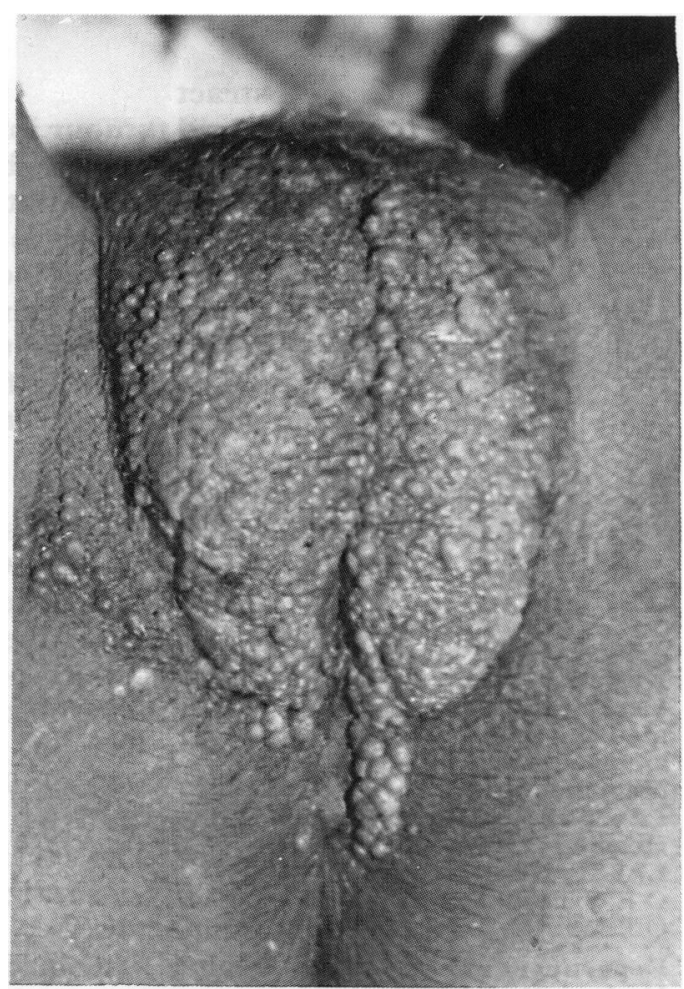

Figure Lymphangioma circumscriptum of vulva showing thin walled translucent vesicles resembling frog spawn.

Among the cases of vulval lymphangioma circumscriptum reported, two cases were described following radiotherapy for squamous cell carcinoma of cervix. ${ }^{34} \mathrm{~A}$ third case reported by Abu-Hamad $e t a l^{5}$ had no previous history of surgery or radiotherapy. In the fourth case reported by Sood $e t a l^{6}$ past history of surgery and treatment of pulmonary tuberculosis and scars near the left cervical and vaginal region were also present. In the present case there was no history of tuberculosis elsewhere, or history of surgery. Recurrences are common.

The differential diagnosis includes genital warts, tuberculosis verucosa cutis, ${ }^{8}$ lymphogranuloma venereum (LGV) and filariasis.

1 Moschella SL, Pillsburry DM, Hurley HJ. Dermatology, Philadelphia. WB Saunders Company 1975.

2 Domontaz AN. Andrews Diseases of Skin 6th Asian ed. Tokyo, Igaku Stoin Ltd. 1971.

3 Fisher I, Orkin M. Acquired lymphangioma-report of a case. Arch Dermatol 1970:101:230-4.

4 Lapolla J, Foucar E, Leshin B, Whitaker D, Anderson B. Vulvar lymphangioma circumscriptum a rare complication of therapy for squamous cell carcinoma of the cervix. Gynaecol Oncol 1985;22:363-6.

5 Abu-Hamad A, Provencher D, Ganjee P, Penaher M Lymphangioma circumscriptum of the vulva; a case report and review of the literature. Obstet Gynecol 1989;73:496-9.

6 Sood M, Mandal AK, Ganesh K. Lymphangioma circumscriptum of the vulva. $f$ Indian Med Assoc 1991;89:262-3.

7 Flanagan BP, Helwig EB. Cutaneous lymphangioma Arch Dermatol 1977;113:24-30.

8 Murugan S, Kaleelullah MCA. Vulval tuberculosis with esthiomene. Ind $\mathcal{F}$ Tuberculosis 1988;35:32-3. 